\title{
Cyclodextrin Polymers with Nitrogen-Containing Tripodal Crosslinkers for Efficient PFAS Adsorption
}

Anna Yang, ${ }^{1}$ Casey Ching, ${ }^{2}$ Maeghan Easler, ${ }^{3}$ Damian E. Helbling, ${ }^{2 *}$ William R. Dichtel ${ }^{1 *}$

${ }^{1}$ Department of Chemistry, Northwestern University, Evanston, IL, 60208 USA

${ }^{2}$ School of Civil and Environmental Engineering, Cornell University, Ithaca, NY 14853 USA

${ }^{3}$ Department of Biochemistry, Biophysics and Molecular Biology, Iowa State University, Ames, IA 50011 USA

\begin{tabular}{|c|}
\hline Correspondence Addresses \\
\hline Prof. William R. Dichtel \\
Department of Chemistry \\
Northwestern University \\
2145 Sheridan Road \\
Evanston, IL 60208 (USA) \\
wdichtel@ @orthwestern.edu \\
Prof. Damian E. Helbling \\
Cornell University \\
Ithaca, NY 14853 (USA) \\
damian.helbling@ cornell.edu \\
\hline
\end{tabular}

$\begin{array}{lll}\text { S.1 Materials and Instruments } & \text { S2 }\end{array}$

$\begin{array}{lll}\text { S.2 } & \text { Linker Synthesis and Characterization } & \text { S4 }\end{array}$

$\begin{array}{lll}\text { S.3 } & \text { Polymer Synthesis and Optimization } & \text { S8 }\end{array}$

$\begin{array}{lll}\text { S.4 Materials Characterization } & \text { S10 }\end{array}$

$\begin{array}{lll}\text { S.5 } & \text { Batch Adsorption Studies } & \text { S12 }\end{array}$

S.6 Comparison of PFOA and GenX Soprtion $\quad$ S18

$\begin{array}{llr}\text { S.7 } & \text { References } & \text { S18 }\end{array}$ 


\section{S.1 Materials and Instruments}

Materials. All reagents were obtained from commercial suppliers and used as received unless otherwise noted. Tris(2-aminoethyl)amine, sodium borohydride, triethylamine, 2,3,4,5,6pentafluorobenzoyl chloride, and pentafluorobenzaldehyde were purchased from Sigma Aldrich. $\beta$-cyclodextrin ( $\beta$-CD, $\geq 97 \%$ ) was purchased from Sigma Aldrich and dried at $100{ }^{\circ} \mathrm{C}$ in a vacuum overnight and kept under desicator before usage. Anhydrous solvents (THF, $\mathrm{CH}_{3} \mathrm{OH}$, and DMSO) were obtained from a solvent purification system (JC Myer System). Inorganic syringe filter $(0.2$ $\mu \mathrm{m})$ was purchased from Whatman. Cellulose acetate filter $(0.45 \mu \mathrm{m})$ was purchased from Restek. Nylon membrane filter $(0.45 \mu \mathrm{m}, 47 \mathrm{~mm})$ used for collecting polymer adsorbents was purchased from MAGNA, Maine Manufacturing LLC. Triopodal linker $\mathbf{1}^{1}$ and $\mathbf{2}^{2}$ were prepared using literature procedures.

Instruments. Solution ${ }^{1} \mathrm{H}$ and ${ }^{19} \mathrm{~F}$ NMR spectra were obtained on a $400 \mathrm{MHz}$ Bruker Avance III HD Nanobay system equipped with SampleXpress autosampler. All NMR spectra were recorded at room temperature $(298 \mathrm{~K})$ and chemical shifts were referenced on residual solvent peaks ( $\mathrm{CDCl}_{3}: 7.26 \mathrm{ppm}$ for $\left.{ }^{1} \mathrm{H} \mathrm{NMR}\right)$.

Elemental analysis was performed by Robertson Microlit Laboratories. Combustion analysis was used for carbon, hydrogen, and nitrogen elemental analysis, and fluorine was analyzed using ion-selective electrode methodology.

Infrared spectroscopy was performed using a Nicolet iS10 FT-IR spectrometer equipped with a Diamond ATR.

The supercritical $\mathrm{CO}_{2}$ samples were dried using a Leica EM CPD 300. Prior to the supercritical drying process, all samples were Soxhlet extracted in tea bags in methanol, and wet samples were placed into the drying champer. The drying chamber was cooled to $15^{\circ} \mathrm{C}$ and filled 
with $\mathrm{CO}_{2}$ at the "fast" setting rate. A delay of 120 seconds was used with an exchange speed of "5" for 20 cycles of $\mathrm{CO}_{2}$ exchange. The temperature was raised to $30{ }^{\circ} \mathrm{C}$ on the "slow" setting, then the pressure was released on the "slow $20 \%$ " setting.

Surface Area Analysis was performed on a Micromeritics ASAP 2420 Accelerated Surface Area and Porosity Analyzer using 20-40 mg of polymer loading. Samples in oven dried analysis tubes were capped with a Transeal then degassed at $100{ }^{\circ} \mathrm{C}$ until the offgas rate was less than 2.0 $\mu \mathrm{mHg} / \mathrm{min}$. Isotherms were performed using ultrahigh purity $\mathrm{N}_{2}$. The isotherms were generated by incremental exposure to nitrogen up to $760 \mathrm{mmHg}(1 \mathrm{~atm})$ at $77 \mathrm{~K}$. surface areas $\left(S_{\mathrm{BET}}\right)$ were calculated based on the linear region $\left(P / P_{0}\right.$ of $\left.0.05-0.15\right)$ of the isotherm using Brunauer-EmmettTeller adsorption models included in the instrument software (Micromeritics ASAP-2420 V4.00).

Quantification of GenX (200 $\mu \mathrm{g} \mathrm{L}^{-1}$ to $\left.200 \mathrm{mg} \mathrm{L}^{-1}\right)$ and PFOA (200 $\mu \mathrm{g} \mathrm{L}^{-1}$ to $200 \mathrm{mg} \mathrm{L}^{-1}$ ) from the batch adsorption studies for kinetic experiments and isotherm experiments was performed using Agilent 1200 Series high performance liquid chromatography (HPLC) coupled with an ESIion trap mass spectrometer (MS) Bruker Amazon X (USA). The mobile phase consisted of (A) nanopure water and (B) HPLC-grade methanol: nanopure water $=85: 15$, both with $10 \mathrm{mM}$ ammonium acetate (Sigma Aldrich, USA). $5 \mu \mathrm{L}$ (GenX) and $20 \mu \mathrm{L}$ (PFOA) of samples were injected and loaded onto a ZORBAX Eclipse Plus C18 column ( $2.1 \mathrm{~mm}$ x $50 \mathrm{~mm}$, particle size 3.5 $\mu \mathrm{m}$, Agilent, Santa Clara, CA) with $85 \%$ (B) mobile phase at $400 \mu \mathrm{L} \mathrm{min}{ }^{-1}$ pumping rate. The column was warmed at $40{ }^{\circ} \mathrm{C}$. The HPLC-MS was operated with electrospray ionization in negative polarity mode. Seven matrix-matched calibration standards were prepared with concentrations ranging between $10 \mu \mathrm{g} \mathrm{L}^{-1}$ to $200 \mu \mathrm{g} \mathrm{L}^{-1}$ to generate external calibration curve, which was used for quantifying analytes. 
Quantification of PFAS from the adsorption studies at $[\mathrm{PFAS}]_{0}=1 \mu \mathrm{g} \mathrm{L}^{-1}$ in Milli-Q water was conducted using large-volume injection and high performance liquid chromatography (HPLC) coupled with a quadrupole-orbitrap mass spectrometer (QExactive, ThermoFisher Scientific). Briefly, the mobile phase consisted of (A) LCMS-grade water amended with $20 \mathrm{mM}$ ammonium acetate and (B) LCMS-grade methanol. Samples were injected at $5 \mathrm{~mL}$ volumes onto a Hypersil Gold dC18 $12 \mu \mathrm{m} 2.1$ x 20 mm trap column (ThermoFisher Scientific) and were eluted onto an Atlantis dC18 $5 \mu \mathrm{m} 2.1 \times 150 \mathrm{~mm}$ analytical column (Waters) with a gradient pump delivering $300 \mu \mathrm{L} \min ^{-1}$ of a mobile phase gradient starting at $40 \% \mathrm{~B}$. The column temperature was held constant at $25^{\circ} \mathrm{C}$. The HPLC-MS was operated with electrospray ionization in negative polarity mode. Matrix-matched calibration standards $(n=9)$ were prepared with concentrations ranging between $0 \mathrm{ng} \mathrm{L}^{-1}$ to $1000 \mathrm{ng} \mathrm{L}^{-1}$ and spiked with a mixture of six isotope labelled internal standards (ILISs). Analytes were quantified from calibration standards based on the PFAS target-to-ILIS peak area ratio responses by linear least-squares regression. Calibration curves were run at the beginning of the analytical run. Instrument blanks were run before and after the calibration curve and each batch of triplicate samples.

Thermogravimetric analyses were performed in a Netzsch STA 449 F3 Jupiter Simultaneous Thermal Analysisi (STA) instrument. 18 and $20 \mathrm{mg}$ of CDP1 and CDP2 were placed in an Alumina crucible respectively. Samples were measured under ultra-high purity Helium gas (50 ml/min). Buoyancy effect for Helium was corrected by measuring the empty crucible under the same measurement conditions used for the samples. Temperature was increased at a rate of 10 ${ }^{\circ} \mathrm{C} / \mathrm{min}$ from 45 to $600{ }^{\circ} \mathrm{C}$. Performance of the thermobalance of the STA was verified by using a certified sample of calcium oxalate monohydrate (European Pharmacopoeia Reference Standard ) up to $1000{ }^{\circ} \mathrm{C}$. 


\section{S.2 Linker Synthesis and Characterization}

\section{Linker synthesis.}

Scheme S1. Syntheses of tripodal linkers 1 and 2.
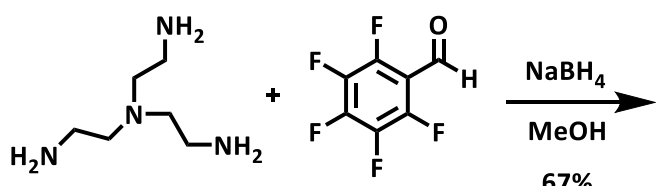

$67 \%$
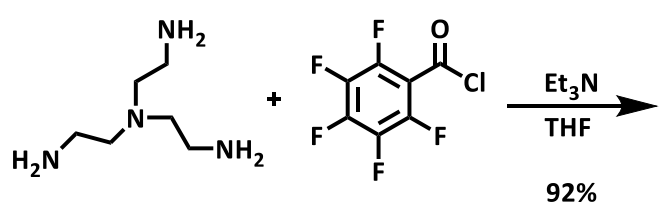
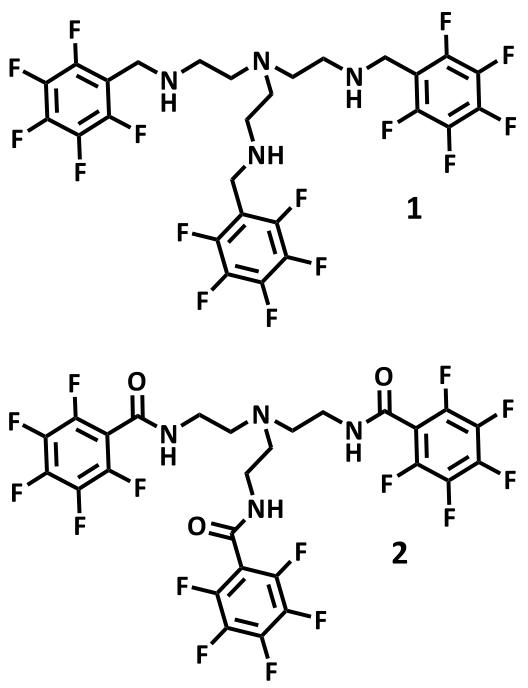

(1) was prepared following a literature procedure ${ }^{1}$ : To a solution of pentafluorobenzaldehyde (1.764 g, $9 \mathrm{mmol}, 3$ equiv) in $50 \mathrm{~mL}$ of dry methanol, a solution of tris(2-aminoethyl)amine (TREN, $0.438 \mathrm{~g}, 3 \mathrm{mmol}, 1$ equiv) in $30 \mathrm{~mL}$ of dry mehthanol was added drop wise over a period of $30 \mathrm{~min}$ under nitrogen at room temperature. After stirring for $24 \mathrm{~h}$, the solution was cooled in ice bath and excess $\mathrm{NaBH}_{4}(0.454 \mathrm{~g}, 12 \mathrm{mmol}, 4$ equiv) was added in small portion. The solution was allowed to stir for another $4 \mathrm{~h}$, then refluxed for $2 \mathrm{~h}$. Methanol was removed under reduced pressure and the residue was extracted with chloroform and water. The collected organic layers were dried with anhydrous sodium sulphate and evaporated under reduced pressure. Compound was purified by column chromatography using dichloromethane/methanol (9.5/0.5) as eluent to give off-yellow solid (1.38 g, 67\% yield). IR (ATR): 2844.13 (Aliphatic N-C stretch), 1494.63 (Aromatic $\mathrm{C}=\mathrm{C}$ stretch), 1134.95 (Aromatic $\mathrm{C}-\mathrm{F}$ stretch) $\mathrm{cm}^{-1}$. NMR data was consistent with those previously reported. ${ }^{1}$

(2) was prepared following a literature procedure ${ }^{2}$ : To a $250 \mathrm{~mL}$ of round bottom flask, tris(2aminoethyl)amine (TREN, $1 \mathrm{~g}, 6.8 \mathrm{mmol}, 1$ equiv) was dissolved in $75 \mathrm{~mL}$ of dry tetrahydrofurane (THF). Dry triethylamine (TEA, $3 \mathrm{~mL}, 21.5 \mathrm{mmol}, 3.16$ equiv) was added to the mixture and the 
mixture was allowed to stir at room temperature in nitrogen atmosphere for $5 \mathrm{~min}$. Then, 2,3,4,5,6pentafluorobenzoyl chloride (4.63 g, $20 \mathrm{mmol}, 2.95$ equiv) dissolved in $50 \mathrm{~mL}$ of dry THF was added dropwise through pressure equalizing funnel over $1 \mathrm{~h}$. The mixture was allowed to stir at room temperature for another $14 \mathrm{~h}$. The white triethylammonium chlroride salt was filtered out and washed with cold THF three times. The solvent was removed under reduced pressure at $40{ }^{\circ} \mathrm{C}$ to yield yellow oil. The oil redissolved in $50 \mathrm{~mL}$ of dichloromethane (DCM) was washed once with saturated $\mathrm{NaCl}$ solution and three times with distilled water. The organic layer separated, collected, dried over anhydrous sodium sulfate. The solvent was removed under reduced pressure to yield off yellow solid. The solid was recrystallized in hot DCM to give colorless crystals (4.5 g, 92\%). IR (ATR): 3241.89 ( $\mathrm{N}-\mathrm{H}$ stretch), 1651.32 (C=O stretch), 1481.61 (Aromatic C=C stretch), 1147.97 (Aromatic C-F stretch) $\mathrm{cm}^{-1}$. NMR data was consistent with those previously reported. ${ }^{2}$

\section{${ }^{1} \mathrm{H}$ and ${ }^{19} \mathrm{~F}$ NMR.}
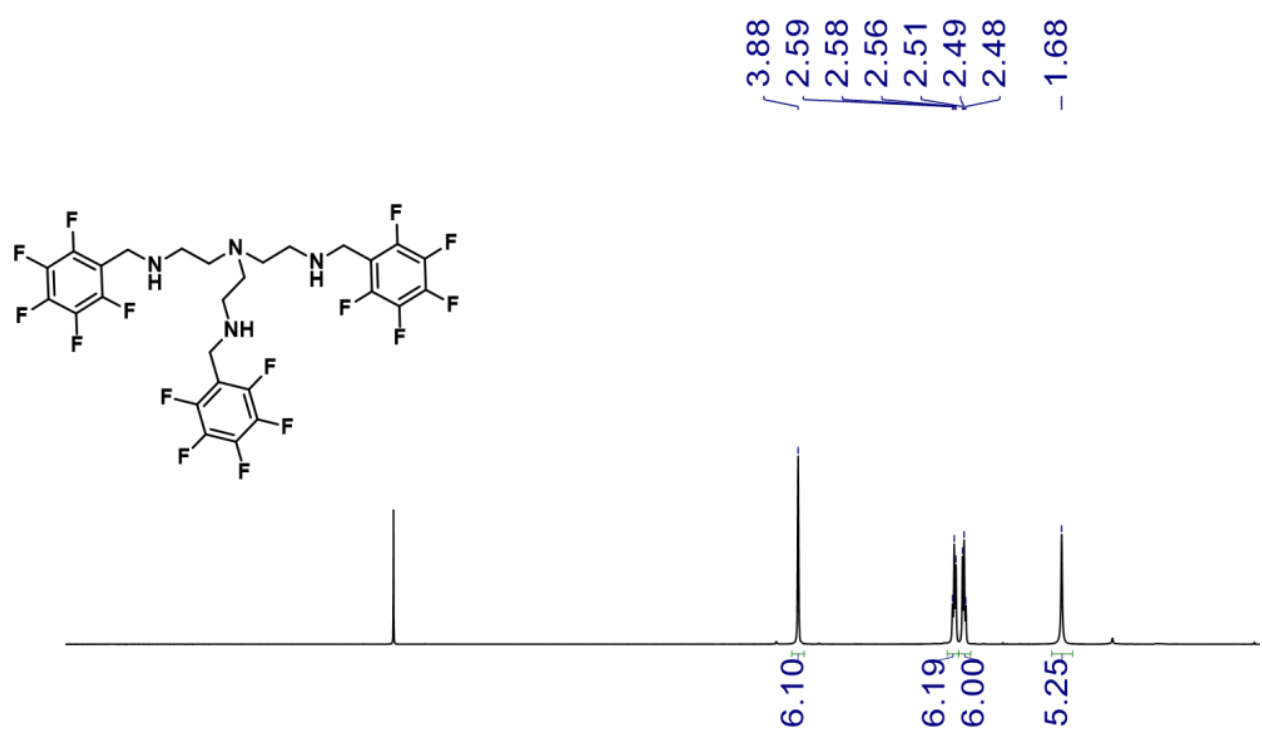

\begin{tabular}{lllllllll}
\hline 0 & 9 & 8 & 7 & $\begin{array}{c}6 \\
\text { Chemical shift / ppm }\end{array}$ & $\begin{array}{c}4 \\
\text { Chemical }\end{array}$
\end{tabular}

Figure S1. ${ }^{1} \mathrm{H}$ NMR spectrum of $1\left(400 \mathrm{MHz}, \mathrm{CDCl}_{3}\right)$. 


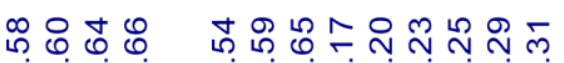

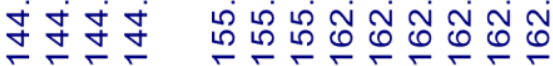

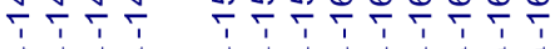
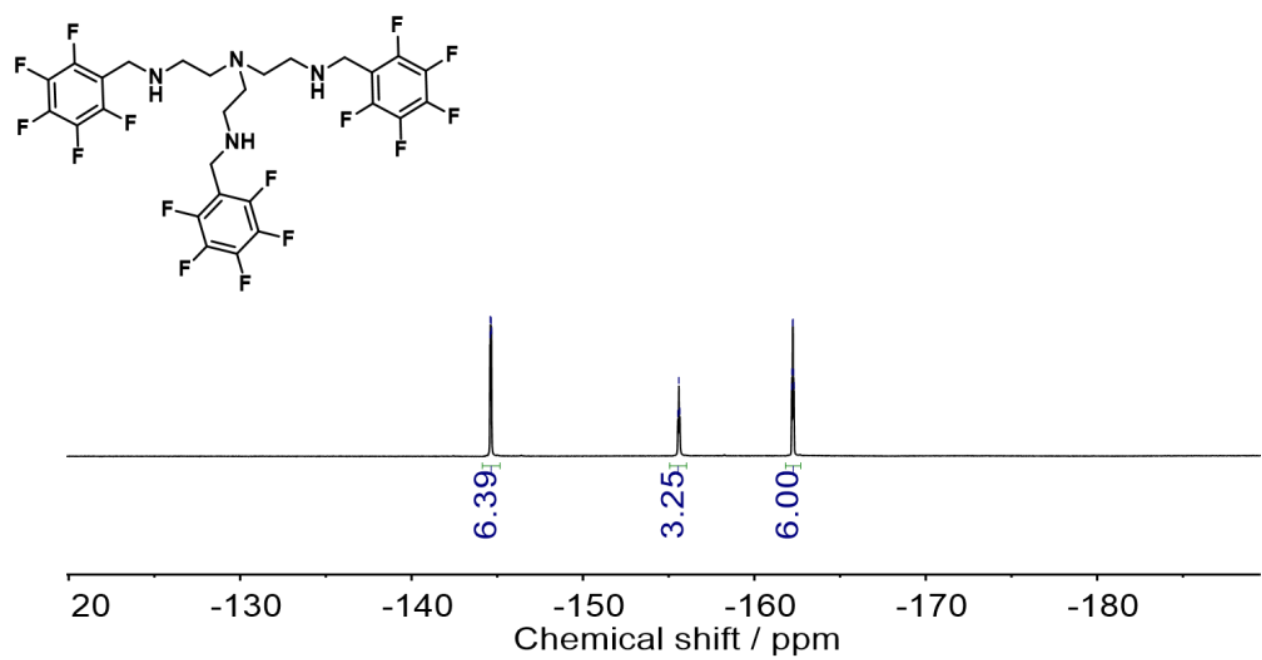

Figure S2. ${ }^{19} \mathrm{~F}$ NMR spectrum of $1\left(376 \mathrm{MHz}, \mathrm{CDCl}_{3}\right)$.

กำ

$N N$

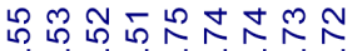

लं लं $N$ N $N$ N
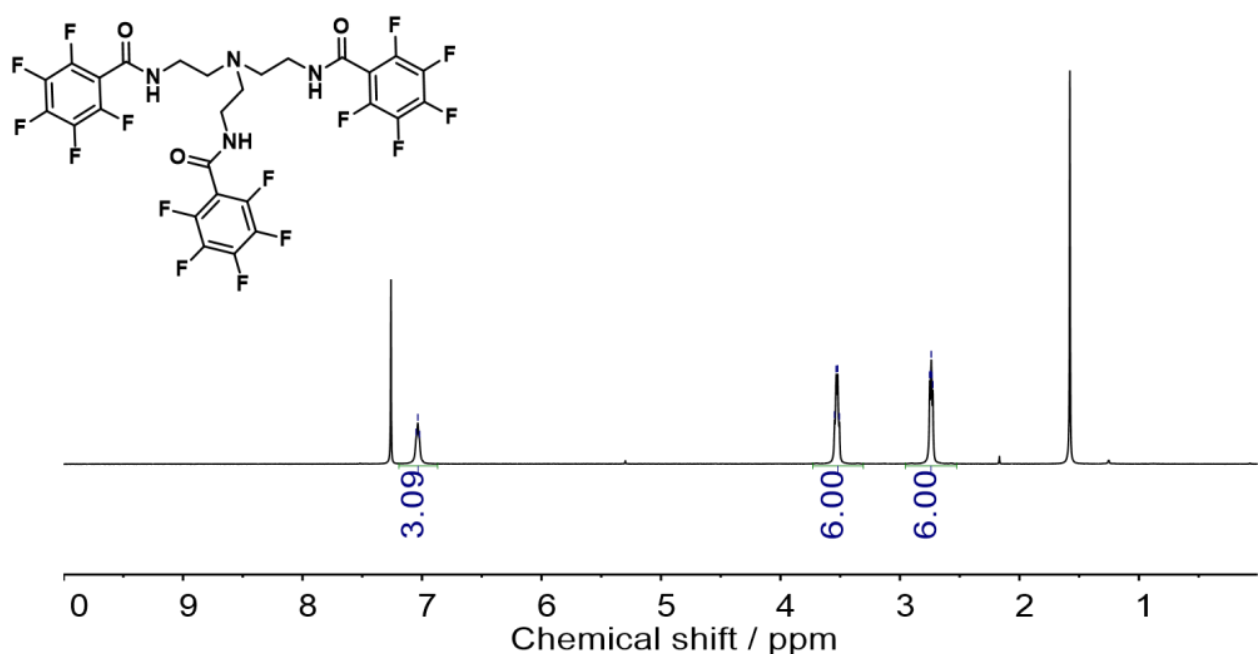

Chemical shift / ppm

Figure S3. ${ }^{1} \mathrm{H}$ NMR spectrum of $2\left(400 \mathrm{MHz}, \mathrm{CDCl}_{3}\right)$. 
ก

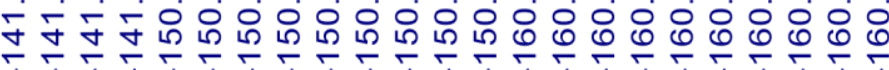
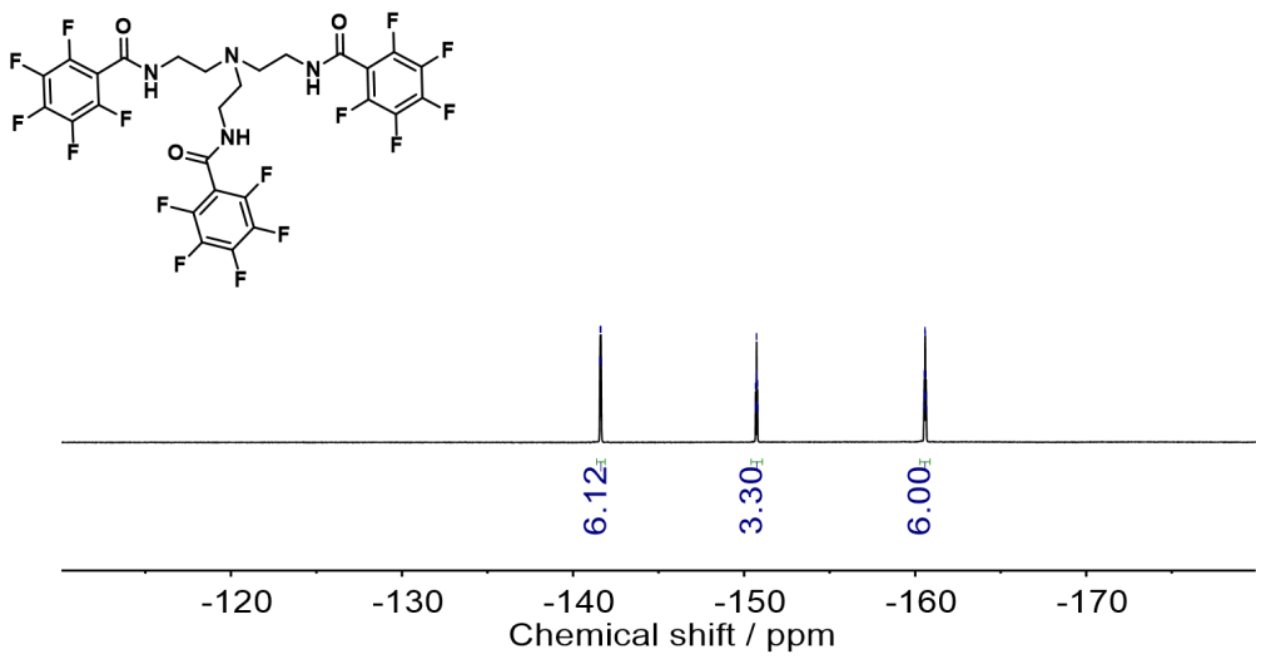

Figure S4. ${ }^{19} \mathrm{~F}$ NMR spectrum of $2\left(376 \mathrm{MHz}, \mathrm{CDCl}_{3}\right)$.

\section{S.3 Polymer Synthesis and Optimization}

\section{General Polymer Synthesis.}

General procedure for polymer synthesis follows: In an oven dried $20 \mathrm{~mL}$ scintillation vial equipped with a magnetic stir bar, $\beta-\mathrm{CD}$, tripodal linker, base and anhydrous DMSO were charged. The vial was placed on a pre-heated hot stirring plate $\left(85^{\circ} \mathrm{C}\right)$ and stirred at $500 \mathrm{rpm}$ for 24 hours. The vial was cooled and the crude was filtered and acidified by adding $1 \mathrm{M} \mathrm{HCl}$ until the solution reaches $\mathrm{pH} 1-3$, then stirred for $30 \mathrm{~min}$. The solid was then washed by stirring in deionized $\mathrm{H}_{2} \mathrm{O}$ $(2 \times 10 \mathrm{~mL})$ for $20 \mathrm{~min}$, THF $(2 \times 10 \mathrm{~mL})$ for $10 \mathrm{~min}$, and $\mathrm{CH} 2 \mathrm{Cl} 2(1 \times 10 \mathrm{~mL})$ for $10 \mathrm{~min}$. The filtered solid was packed into a teabag and activated by Soxhlet extraction with methanol for 1 day. Then the solid was dried with super critical $\mathrm{CO}_{2}$ to give yellow powder.

Different polymerization parameters such as 1) $\beta$-CD to linker feed ratio, 2) base, 3) varying amount of base, and 4) solvent were screened. (Table S1). High yielding and fast gelling polymer was obtained with 1:2 feed ratio of $\mathrm{CD}$ :linker and $\mathrm{K}_{2} \mathrm{CO}_{3}$ (20 equiv) in $0.15 \mathrm{M}$ anhydrous DMSO. 
Table S1. Reaction optimization based on fast gelling and high yielding polymerization.

\begin{tabular}{c|ccccc}
\hline Trial & $\begin{array}{c}\beta \text {-CD:1 } \\
\text { ratio }\end{array}$ & $\begin{array}{c}\text { Solvent } \\
(\mathrm{M})\end{array}$ & $\begin{array}{c}\text { Bases } \\
\text { (Equiv) }\end{array}$ & Observation & $\begin{array}{c}\text { Yield } \\
(\%)\end{array}$ \\
\hline a) & $1: 0.5$ & $0.15 \mathrm{M}$ & $\mathrm{K}_{2} \mathrm{CO}_{3}, 20$ equiv & $\begin{array}{c}\text { No precipitation } \\
(72 \mathrm{~h})\end{array}$ & $\mathrm{NA}$ \\
b) & $1: 1$ & $0.15 \mathrm{M}$ & $\mathrm{K}_{2} \mathrm{CO}_{3}, 20$ equiv & Hydrogel & $\mathrm{NA}$ \\
c) & $1: 2$ & $0.15 \mathrm{M}$ & $\mathrm{K}_{2} \mathrm{CO}_{3}, 20$ equiv & Polymer $(<3 \mathrm{~h})$ & 96 \\
d) & $1: 3$ & $0.15 \mathrm{M}$ & $\mathrm{K}_{2} \mathrm{CO}_{3}, 20$ equiv & Polymer $(24 \mathrm{~h})$ & 78 \\
e) & $1: 4$ & $0.15 \mathrm{M}$ & $\mathrm{K}_{2} \mathrm{CO}_{3}, 20$ equiv & Hydrogel & $\mathrm{NA}$ \\
\hline f) & $1: 2$ & $0.05 \mathrm{M}$ & $\mathrm{K}_{2} \mathrm{CO}_{3}, 20$ equiv & No precipitation & $\mathrm{NA}$ \\
& & & & $(72 \mathrm{~h})$ & \\
g) & $1: 2$ & $0.15 \mathrm{M}$ & $\mathrm{K}_{2} \mathrm{CO}_{3}, 20$ equiv & Polymer $(<3 \mathrm{~h})$ & 96 \\
\hline h) & $1: 2$ & $0.15 \mathrm{M}$ & $\mathrm{Cs}_{2} \mathrm{CO}_{3}, 9$ equiv & Polymer $(24 \mathrm{~h})$ & 81 \\
i) & $1: 2$ & $0.15 \mathrm{M}$ & $\mathrm{Cs}_{2} \mathrm{CO}_{3}, 15$ equiv & Polymer $(24 \mathrm{~h})$ & 70 \\
j) & $1: 2$ & $0.15 \mathrm{M}$ & $\mathrm{Cs}_{2} \mathrm{CO}_{3}, 20$ equiv & Polymer $(<1.5 \mathrm{~h})$ & 68 \\
k) & $1: 2$ & $0.15 \mathrm{M}$ & $\mathrm{Cs}_{2} \mathrm{CO}_{3}, 25$ equiv & Polymer $(<0.5 \mathrm{~h})$ & 61 \\
\hline
\end{tabular}

\section{Optimized Polymer Synthesis.}

CDP1: An oven dried $20 \mathrm{~mL}$ scintillation vial equipped with a magnetic stir bar was charged with $\beta$-CD (0.624 g, $0.55 \mathrm{mmol}, 1$ equiv), 1 (0.755 g, $1.1 \mathrm{mmol}, 2$ equiv), K2CO3 (1.520 g, $11 \mathrm{mmol}$, 20 equiv) and $3.6 \mathrm{~mL}$ anhydrous DMSO. The vial was placed on a pre-heated hot stirring plate (85 ${ }^{\circ} \mathrm{C}$ ) and stirred at $500 \mathrm{rpm}$ for 24 hours. The gelation is observed within 3 hours. The vial was cooled and the crude was filtered and neutralized by $1 \mathrm{M} \mathrm{HCl}$, then the solid was washed by stirring in deionized $\mathrm{H} 2 \mathrm{O}(2 \times 10 \mathrm{~mL})$ for $10 \mathrm{~min}$, THF $(2 \times 10 \mathrm{~mL})$ for $10 \mathrm{~min}$, and $\mathrm{CH} 2 \mathrm{Cl} 2(1 \times 10 \mathrm{~mL})$ for $10 \mathrm{~min}$. The filtered solid was packed into a teabag and activated by Soxhlet extraction with methanol for 1 day. Then the solid was dried with super critical $\mathrm{CO}_{2}$ to give yellow powder (1.256 g, 96\% yield). Elemental analysis: C, 42.40; H, 4.64; N, 3.87; F, 16.74. IR (ATR): 3356.64 (O-H stretch), 2936.21 (Aliphatic C-H stretch), 1494.63 (Aromatic C=C stretch), 1134.95 (Aromatic CF stretch), 1020.20 (C-O stretch) $\mathrm{cm}^{-1}$. S BET: $159 \mathrm{~m}^{2} \mathrm{~g}^{-1}$. 
CDP2: Followed a same procedure as CDP1. An oven dried $20 \mathrm{~mL}$ scintillation vial equipped with a magnetic stir bar was charged with $\beta$-CD (0.624 g, $0.55 \mathrm{mmol}, 1$ equiv), 2 (0.800 g, 1.1 mmol, 2 equiv), K2CO3 (1.520 g, $11 \mathrm{mmol}, 20$ equiv) and $3.6 \mathrm{~mL}$ anhydrous DMSO. The vial was placed on a pre-heated hot stirring plate $\left(85^{\circ} \mathrm{C}\right)$ and stirred at $500 \mathrm{rpm}$ for 24 hours. The gelation is observed within 1 hours. The vial was cooled and the crude was filtered and neutralized by $1 \mathrm{M} \mathrm{HCl}$, then the solid was washed by stirring in deionized $\mathrm{H} 2 \mathrm{O}(2 \times 10 \mathrm{~mL})$ for $10 \mathrm{~min}$, THF $(2 \times 10 \mathrm{~mL})$ for $10 \mathrm{~min}$, and $\mathrm{CH} 2 \mathrm{Cl} 2(1 \times 10 \mathrm{~mL})$ for $10 \mathrm{~min}$. The filtered solid was packed into a teabag and activated by Soxhlet extraction with methanol for 1 day. Then the solid was dried with super critical $\mathrm{CO}_{2}$ to give yellow powder (1.262 g, 93\% yield). Elemental analysis: $\mathrm{C}, 44.02 ; \mathrm{H}$, 3.97; N, 4.06; F, 17.28. IR (ATR): 3327.75 (O-H stretch), 2934.77 (Aliphatic C-H stretch), 1651.32 (C=O stretch), 1481.61 (Aromatic $\mathrm{C}=\mathrm{C}$ stretch), 1147.97 (Aromatic C-F stretch), 1022.13 (C-O stretch) $\mathrm{cm}^{-1}$. S $\mathrm{BET}: 63 \mathrm{~m}^{2} \mathrm{~g}^{-1}$.

\section{S.4 Materials Characterization}

\section{Fourier transform-infrared (FT-IR).}

a)

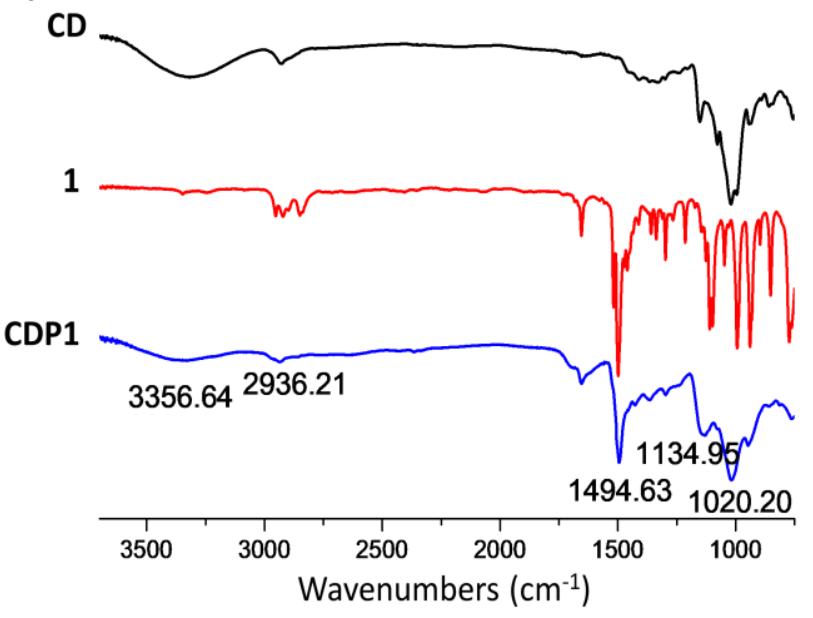

b)

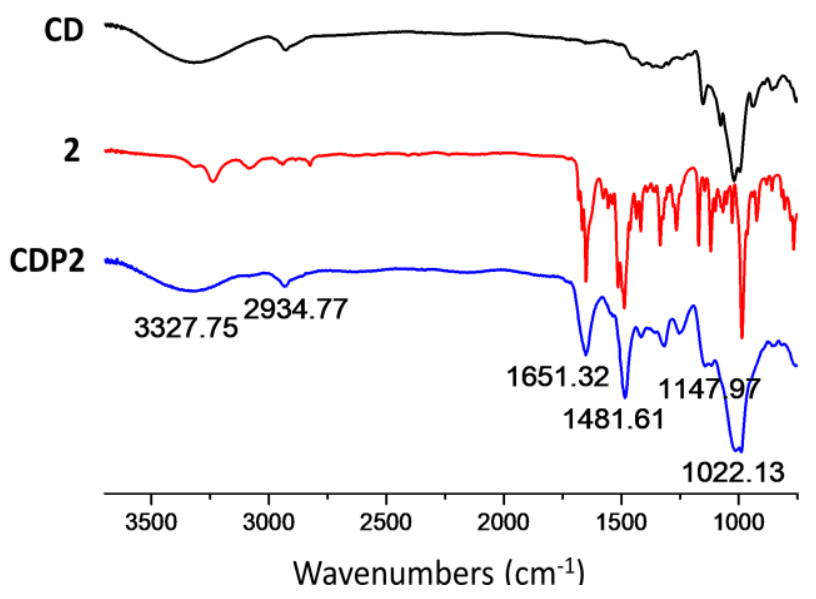

Figure S5. FT-IR spectra $\left(750-3700 \mathrm{~cm}^{-1}\right)$ of a) CD, linker 1, and polymer CDP1, b) CD, linker 2, and polymer CDP2. 
Thermogravimetric Analysis (TGA).
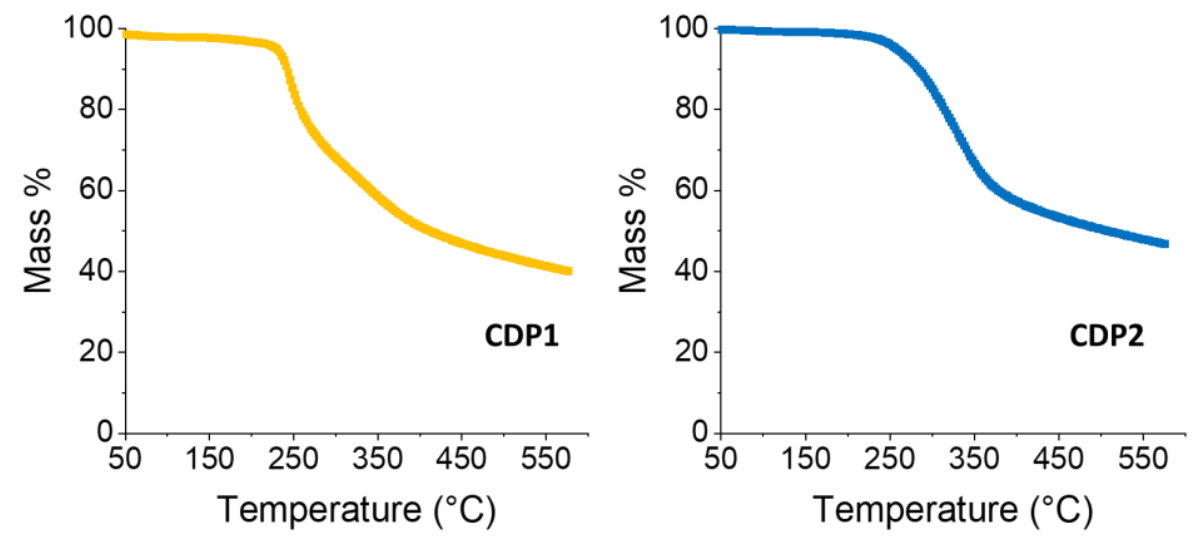

Figure S6. Thermogravimetric analysis (TGA) of CDP1 (yellow) and CDP2 (blue) under helium.

Nitrogen Isotherm and BET Surface Area.
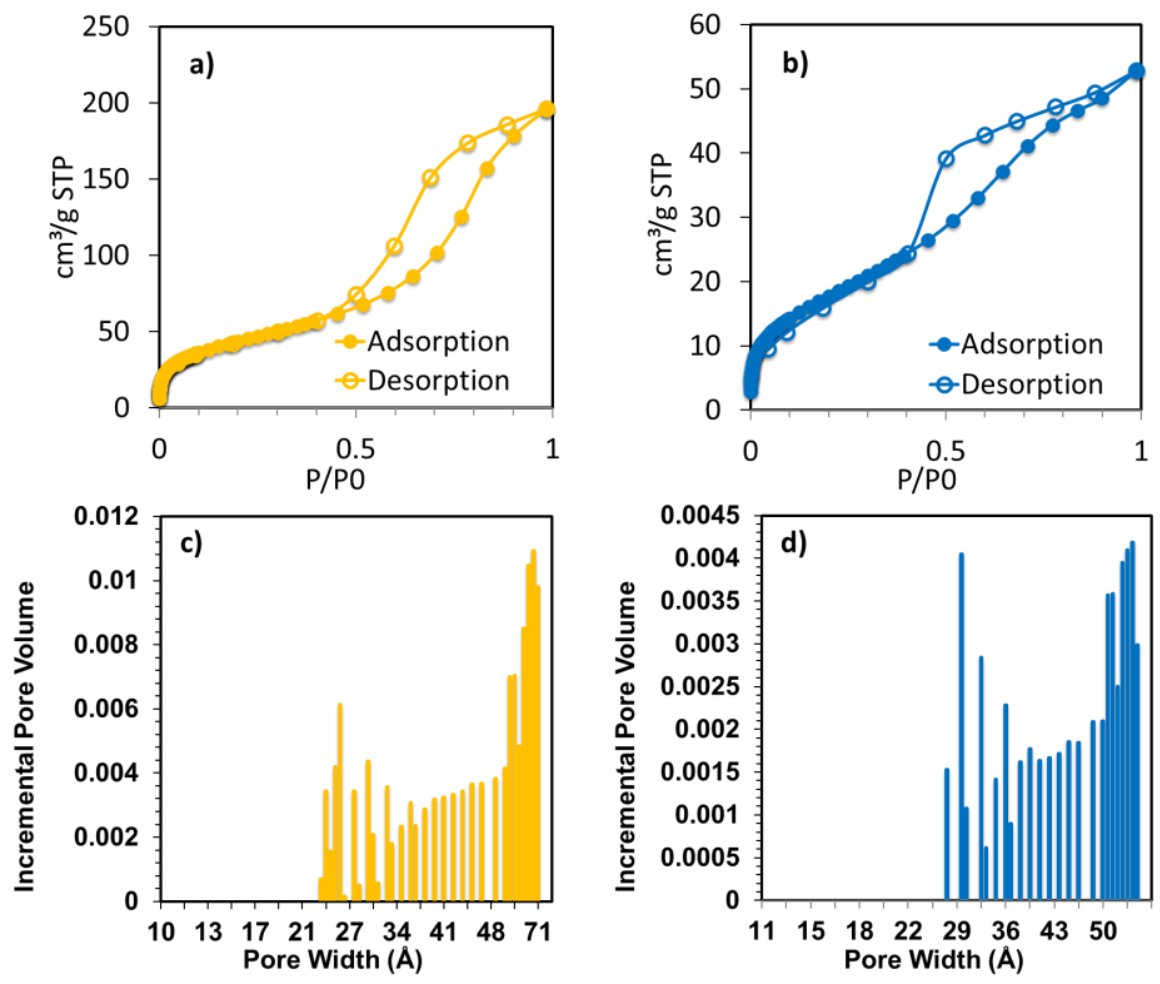

Figure S7. N2 adsorption isotherms of a) CDP1, b) CDP2 and pore size distributions of c) CDP1, and d) CDP2. Solid and open circles represent the adsorption and desorption processes, respectively. 


\section{S.5 Batch Adsorption Studies}

Batch adsorption studies. General batch adsorption experiments of $\mathrm{GenX}^{3}$ and $\mathrm{PFOA}^{4}$ were performed following previous literature procedures. Except for the low concentration batch experiment ( $1 \mu \mathrm{g} \mathrm{L}{ }^{-1}$ pollutant, $10 \mathrm{mg} \mathrm{L}^{-1}$ adsorbent), all batch experiments were conducted in 20 $\mathrm{mL}$ polypropylene scintillaton vials with magnetic stir bars. The vials were stirred at 500 revolutions per minute (rpm) at room temperature. For kinetic studies, GenX was spiked to generate 10 or $200 \mu \mathrm{g} \mathrm{L}^{-1}$ initial adsorption concentration with 100 or $400 \mathrm{mg} \mathrm{L}^{-1}$ adsorbent, respectively. For $\mathrm{pH}$-dependent studies, GenX was spiked to generate $10 \mu \mathrm{g} \mathrm{L}^{-1}$ initial adsorption concentration with $10 \mathrm{mg} \mathrm{L}^{-1}$ adsorbent. We prepared MiliQ water solutions at $\mathrm{pH} 4$ and $\mathrm{pH} 9$ using $0.1 \mathrm{M} \mathrm{NaOH}$ or $\mathrm{HCl}$ solution. $\mathrm{pH}$ values were determined at the beginning and after 24 hours of stirring using Fisherbrand $\mathrm{pH}$ probe (\#FSS35927). For isotherm studies, varying amount of GenX or PFOA was spiked to generated various concentrations of samples with $100 \mathrm{mg} \mathrm{L}^{-1}$ adsorbent. Prior to adsorption experiments, vacuum-dried adsorbents were rehydrated in Milli-Q water, sonicated for $2 \mathrm{~min}$, and stirred for $1 \mathrm{~h}$ at $500 \mathrm{rpm}$ to generate well-suspended solution of adsorbent. All experiments were performed in triplicates along with control samples where no adsorbent was added.

The pollutant removal efficiency (\%) by adsorbents was determined using Eq. S1:

Equation S1: Removal $(\%)=\frac{C_{0}-C_{t}}{C_{0}} * 100$;

where $\mathrm{C}_{0}\left(\mu \mathrm{g} \mathrm{L}^{-1}\right)$ and $\mathrm{C}_{t}\left(\mu \mathrm{g} \mathrm{L}^{-1}\right)$ are the initial and residual concentration at time $(\mathrm{t})$ of pollutant, respectively. The initial concentration $\mathrm{C}_{0}$ was obtained from the average concentration of control samples to account loss of pollutant from experimental conditions.

The amount of pollutant bound to the sorbent $\left(\mathrm{mg} \mathrm{g}^{-1}\right)$ was determined by Eq. S2:

Equation S2: $q_{t}=\frac{C_{0}-C_{t}}{C_{A}}$;

where $\mathrm{q}_{t}\left(\mathrm{mg} \mathrm{g}^{-1}\right)$ is the amount of pollutant adsorbed on the solid phase at any time $\mathrm{t}(\mathrm{h}) ; \mathrm{C} o(\mu \mathrm{g}$ $\left.\mathrm{L}^{-1}\right)$ is the average concentration of pollutant in the control samples; $\mathrm{C}_{t}\left(\mu \mathrm{g} \mathrm{L}^{-1}\right)$ is the residual concentration of pollutant in the solution phase at any sample time $\mathrm{t}(\mathrm{h})$; and $\mathrm{C}_{A}\left(\mathrm{mg} \mathrm{L}^{-1}\right)$ is the concentration of adsorbent used for experiments. 
Kinetic Experiments. The batch kinetic experiments of GenX were conducted with $400 \mathrm{mg} \mathrm{L}^{-1}$ adsorbent in $200 \mu \mathrm{g} \mathrm{L}^{-1}$ of initial GenX concentration for high concentrations and $100 \mathrm{mg} \mathrm{L}^{-1}$ adsorbent in $10 \mu \mathrm{g} \mathrm{L}^{-1}$ of initial GenX concentration for lower concentrtions. For the high concentration, $500 \mathrm{mg} \mathrm{L}^{-1}$ of well-suspended adsorbent solution (8 $\mathrm{mg}$ of polymer in $16 \mathrm{~mL}$ of Milli-Q water) was prepared in a polypropylene vial after sonicating ( $3 \mathrm{~min}$ ) and stirring ( $1 \mathrm{~h}, 500$ rpm). $4 \mathrm{~mL}$ of GenX solution ( $\left.1 \mathrm{mg} \mathrm{L}^{-1}\right)$ was added to each suspension to make total $20 \mathrm{~mL}$ of experimental samples. Samples were collected in $1 \mathrm{~mL}$ volumes at varying time points $(0,10 \mathrm{~min}$, $1.5 \mathrm{~h}$, and $18 \mathrm{~h}$ ) and filtered with a $0.2 \mu \mathrm{m}$ inorganic syringe filter (Whatman). Control samples were also collected after $18 \mathrm{~h}$ to account for GenX losses in same conditions without adsorbent. All batch experiments were performed in triplicates.

a)

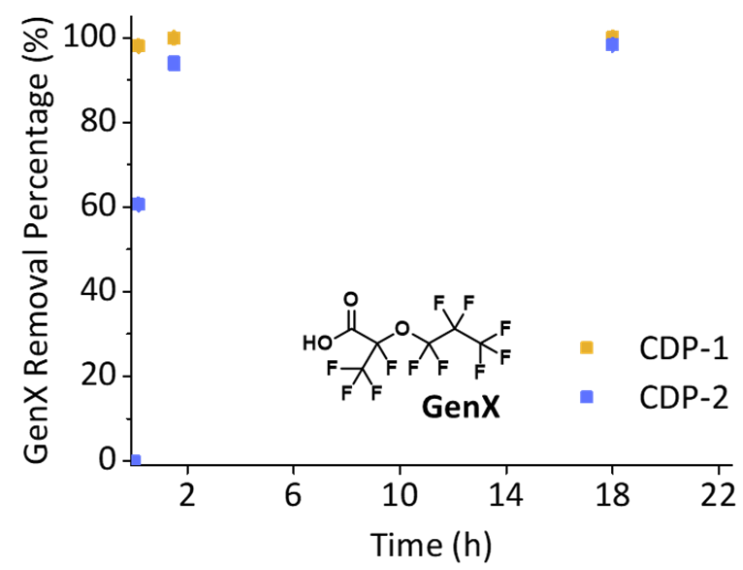

b)

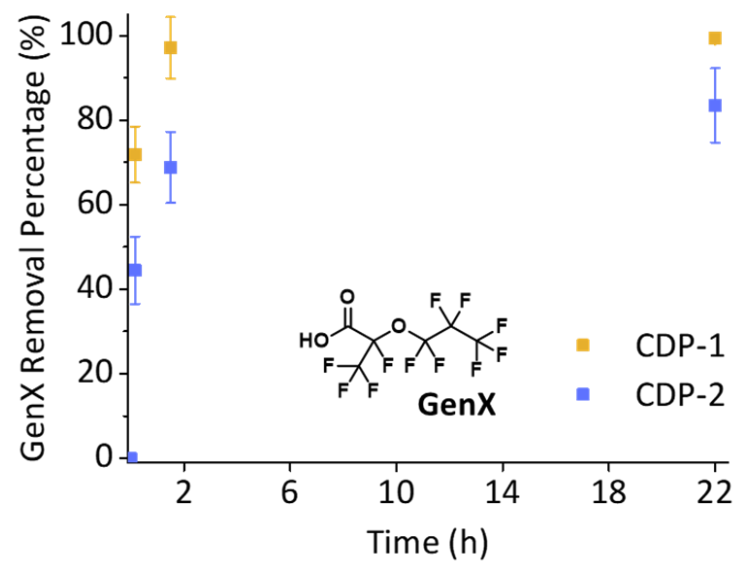

Figure S8. Kinetics of GenX adsorption by CDP1 (yellow) and CDP2 (blue) at a) high concentrations $[\mathrm{GenX}]_{0}=200 \mu \mathrm{g} \mathrm{L}^{-1}$; [Adsorbent $]=400 \mathrm{mg} \mathrm{L}^{-1}$ and b) lower concentrations $[\mathrm{GenX}]_{0}=10 \mu \mathrm{g} \mathrm{L}{ }^{-1}$; [Adsorbent] $=100 \mathrm{mg} \mathrm{L}^{-1}$; Aliquots at $0 \mathrm{~min}, 10 \mathrm{~min}, 1.5 \mathrm{~h}, 18 \mathrm{~h}$; Error bars: standard deviation of 3 experiments.

\section{pH-dependent GenX batch experiments for equilibrium studies.}

The $\mathrm{pH}$-dependent GenX removal experiments were conducted with $10 \mathrm{mg} \mathrm{L}^{-1}$ adsorbent with an initial GenX concentration of $10 \mu \mathrm{g} \mathrm{L}^{-1} .500 \mathrm{mg} \mathrm{L}^{-1}$ of well-suspended adsorbent solution (10 mg of polymer in $20 \mathrm{~mL}$ of Milli-Q water) was prepared in a polypropylene vial after sonicating (3 $\mathrm{min}$ ) and stirring $(1 \mathrm{~h}, 500 \mathrm{rpm})$. To a polypropylene vial, $0.4 \mathrm{~mL}$ of adsorbent solution $(500 \mathrm{mg}$ $\left.\mathrm{L}^{-1}\right), 0.5 \mathrm{~mL}$ of GenX solution $\left(0.4 \mathrm{mg} \mathrm{L}^{-1}\right)$, and $19.1 \mathrm{~mL}$ of MiliQ solution at $\mathrm{pH} 4 \mathrm{or} \mathrm{pH} 9$ were added to make total $20 \mathrm{~mL}$ of experimental samples at two different $\mathrm{pH}$. Samples were collected 
in $1 \mathrm{~mL}$ volumes after 24 hours and filtered with $0.2 \mu \mathrm{m}$ inorganic syringe filter (Whatman). Control samples were also collected after $24 \mathrm{~h}$ to account for GenX losses in same conditions without adsorbent. All batch experiments were performed in triplicates. $\mathrm{pH}$ of samples after 24 hours were determined to give $\mathrm{pH}=3.9,7.2$ and $\mathrm{pH}=3.9,7.9$ for $\mathrm{CDP} 1$ and $\mathrm{CDP} 2$, respectively.

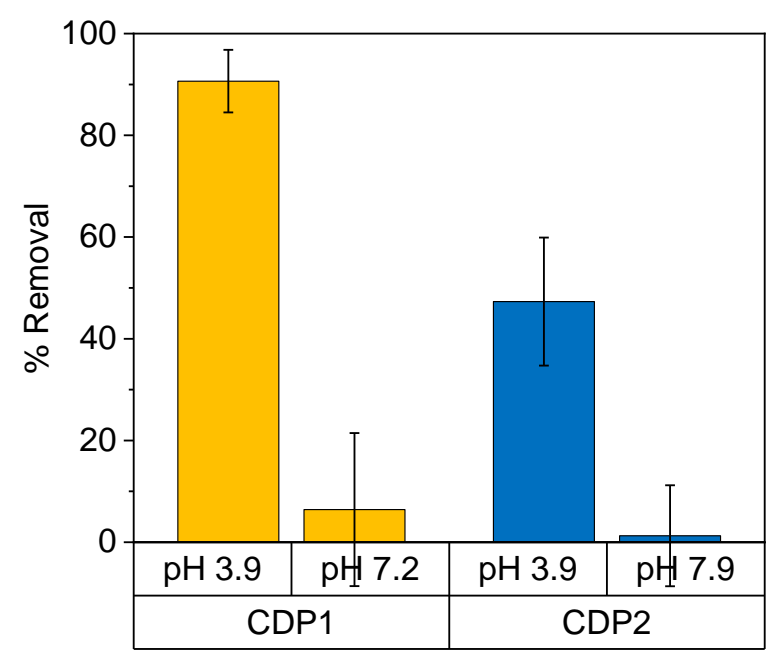

Figure S9. GenX equilibrium removal percentage on CDP1 and CDP2 at different pH. ([GenX] $=10 \mu \mathrm{g} \mathrm{L}^{-1}$; [Adsorbent $]=10 \mathrm{mg} \mathrm{L}^{-1}$ ). Final $\mathrm{pH}$ of solutions was measure and reported after 24 hours from initial solutions at $\mathrm{pH} 4$ and $\mathrm{pH}$ 9. Error bars: standard deviation of 3 experiments.

Low concentration batch experiments of PFAS panel for kinetics and equilibrium studies. The batch experiments at environmentally relevant concentrations of PFAS $\left(1 \mu \mathrm{g} \mathrm{L}^{-1}\right)$ were performed in $15 \mathrm{~mL}$ sacrificial polypropylene centrifuge tubes on a rotary tumbler at $23{ }^{\circ} \mathrm{C}$. A mix of the 10 PFAS was spiked to a volume of $12 \mathrm{~mL}$ of Milli-Q water to achieve $1 \mu \mathrm{g} \mathrm{L} \mathrm{L}^{-1}$ of each PFAS and was mixed overnight. Prior to experiments, vacuum-dried adsorbents were rehydrated in Milli-Q water, sonicated for $1 \mathrm{~min}$, and stirred for $1 \mathrm{~h}$ at $500 \mathrm{rpm}$ to generate a well-suspended solution of adsorbent. Adsorbents were then added to the centrifuge tubes to achieve $10 \mathrm{mg} \mathrm{L}^{-1}$ of adsorbent. Samples were prepared in triplicates and collected at $30 \mathrm{~min}, 9 \mathrm{~h}$, and $48 \mathrm{~h}$. Samples were filtered with $0.45 \mu \mathrm{m}$ cellulose acetate filters (Restek). A mixture of 6 isotope labelled internal standards (ILISs) were spiked to the samples for LC-MS analysis. Control samples were prepared without adsorbent and collected at same time points to account for adsorption losses. 
<smiles>O=C(O)C(F)(F)OC(F)(F)C(F)(F)C(F)(F)F</smiles>

GenX

Perfluoro-2-propoxypropanoic acid<smiles>O=C(O)C(F)(C(F)(F)F)C(F)(F)C(F)(F)F</smiles>

PFBA (C4)

Perfluorobutanoic Acid<smiles>O=C(O)C(F)(F)C(F)(F)C(F)(F)C(F)(F)C(F)(F)F</smiles>

PFHXA (C6)

Perfluorohexanoic Acid<smiles>O=C(O)C(F)(F)C(F)(F)C(F)(F)C(F)(F)C(F)(F)C(F)(F)F</smiles>

PFHpA (C7)

Perfluoroheptanoic Acid

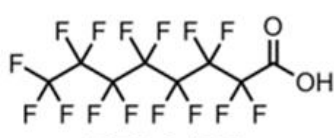

PFOA (C8)

Perfluorooctanoic Acid

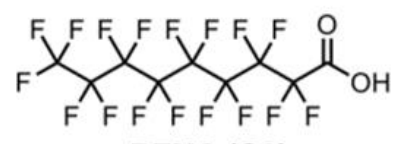

PFNA (C9)

Perfluorononanoic Acid<smiles>O=C(O)C(F)(F)C(F)(F)C(F)(F)C(F)(F)C(F)(F)C(F)(F)C(F)(F)C(F)(F)C(F)(F)F</smiles>

PFDA (C10)

Perfluorodecanoic Acid<smiles>O=S(=O)(O)C(F)(F)C(F)(F)C(F)(F)C(F)(F)F</smiles>

PFBS (C4)

Perfluorobutanesulfonic Acid<smiles>O=S(=O)(O)C(F)(F)C(F)(F)C(F)(F)C(F)(F)C(F)(F)C(F)(F)F</smiles>

PFHxS (C6)

Perfluorohexanesulfonic Acid

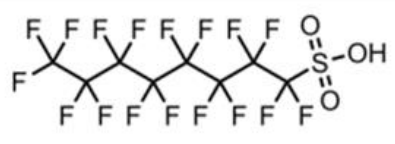

PFOS (C8)

Perfluorooctanesulfonic Acid

Figure S10 A list of ten PFAS tested in an adsorption experiment ([PFAS $]_{0}=1 \mu \mathrm{g} \mathrm{L}^{-1}$; $[\mathrm{CDP}]=$ $\left.10 \mathrm{mg} \mathrm{L}^{-1}\right)$.

a)

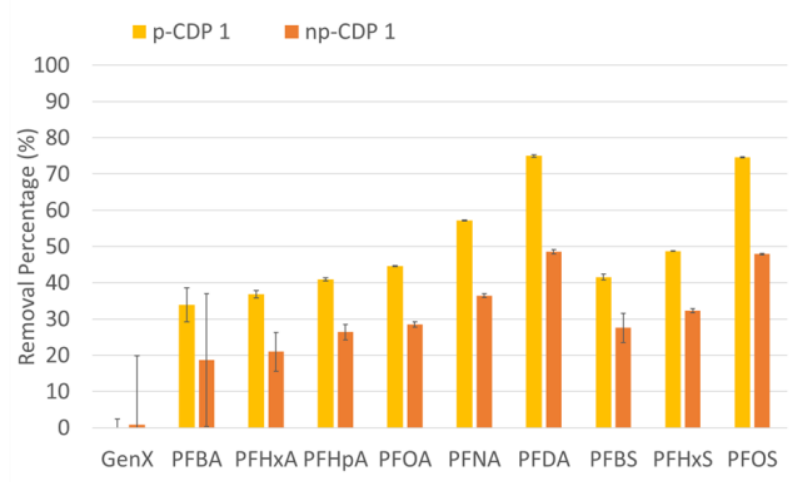

b)

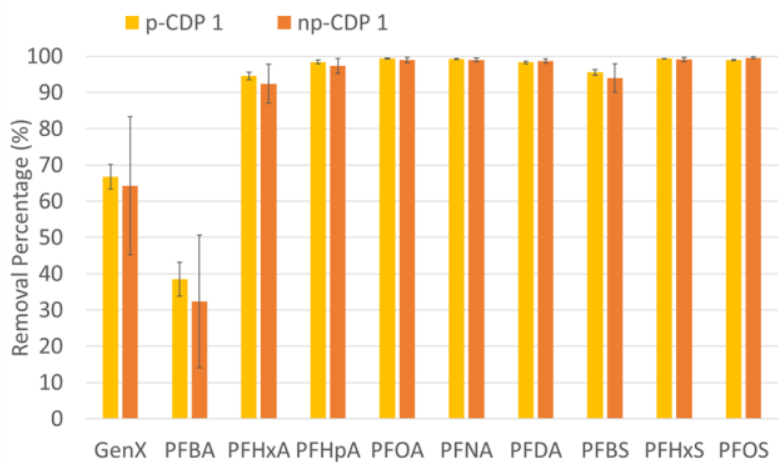

Figure S11. PFAS equilibrium removal percentage on porous CDP1 (yellow) and non-porous CDP1 (orange) after a) $0.5 \mathrm{~h}$ and b) $48 \mathrm{~h}\left([\mathrm{PFAS}]_{0}=1 \mu \mathrm{g} \mathrm{L} \mathrm{L}^{-1}\right.$; [Adsorbent] $\left.=10 \mathrm{mg} \mathrm{L}^{-1}\right)$. Error bars: standard deviation of 3 experiments. 
Isotherm Experiments. $100 \mathrm{mg} \mathrm{L}^{-1}$ of adsorbent dosage was used and GenX or PFOA stock solution was spiked to generate varying initial concentrations. For adsorbent CDP1, initial concentrations of 1, 10, 30, 50, 100, 130, 160, and $200 \mathrm{mg} \mathrm{L}^{-1}$ of GenX, and 30, 50, 70, 100, 130, 160, $200 \mathrm{mg} \mathrm{L}^{-1}$ of PFOA were tested. For adsorbent CDP2, same concentrations resulted in negligible removal efficiency. Thus, concentrations of $1,3,5,8,12,16$, and $20 \mathrm{mg} \mathrm{L}^{-1}$ of PFOA, and $0.01,0.05,0.1,0.2,0.4,0.8$, and $1 \mathrm{mg} \mathrm{L}^{-1}$ of GenX were tested for CDP2. The well-suspended solutions were stirred for $22 \mathrm{~h}$ to reach the equilibrium, $1 \mathrm{~mL}$ volumes of samples were then filtered by $0.2 \mu \mathrm{m}$ inorganic syringe filters (Whatman) to remove any remaining adsorbent. Control experiments to account for GenX losses were performed in the same condition except for the addition of adsorbents, and samples were collected at $22 \mathrm{~h}$. All batch experiments were performed with triplicates.

Langmuir adsorption and Freundlich isotherm fits were generated by Non-linear Least Square Regression in Eq. S3 and Eq. S4:

Equation S3: $\frac{1}{q_{e}}=\frac{1}{q_{m}}+\frac{1}{C_{e} \times q_{m} \times K_{L}} ;$

where $q_{e}\left(\mathrm{mg} \mathrm{g}^{-1}\right)$ is the amount of pollutant adsorbed at equilibrium; $q_{m}\left(\mathrm{mg} \mathrm{g}^{-1}\right)$ is the maximum adsorption capacity of adsorbent at equilibrium; $\mathrm{C}_{e}\left(\mathrm{mg} \mathrm{L}^{-1}\right)$ is the residual pollutant concentration at equilibrium; and $\mathrm{K}_{L}\left(\mathrm{~L} \mathrm{mg}^{-1}\right)$ is the equilibrium constant.

Equation S4: $q_{e}=K_{F} C_{e}^{\frac{1}{n}}$

where $q_{e}\left(\mathrm{mg} \mathrm{g}^{-1}\right)$ is the amount of pollutant adsorbed at equilibrium; $\mathrm{C}_{e}\left(\mathrm{mg} \mathrm{L}^{-1}\right)$ is the residual pollutant concentration at equilibrium; $\mathrm{K}_{F}\left(\mathrm{mg} \mathrm{g}^{-1}\right)\left(\mathrm{L} \mathrm{mg}^{-1}\right)^{1 / \mathrm{n}}$ is the Freundlich constant; and $n$ is an indicator of the intensity of the adsorption.

Table S2. Langmuir and Freundlich parameters derived from plot of the PFOA binding isotherm of CDP2.

Langmuir Fit

Freundlich Fit

\begin{tabular}{|c|c|c|c|c|c|}
\hline $\mathrm{K}_{\mathrm{L}}\left(\mathrm{M}^{-1}\right)$ & $\mathrm{Q}_{\mathrm{M}}(\mathrm{mg} / \mathrm{g})$ & $\mathrm{R}$ & $\mathrm{K}_{\mathrm{F}}(\mathrm{mg} / \mathrm{g})(\mathrm{L} / \mathrm{mg})^{1 / \mathrm{n}}$ & $\mathrm{n}$ & $\mathrm{R}$ \\
\hline $3.3 \times 10^{5}$ & 55 & 0.97 & 5.1 & 1.95 & 0.95 \\
\hline
\end{tabular}




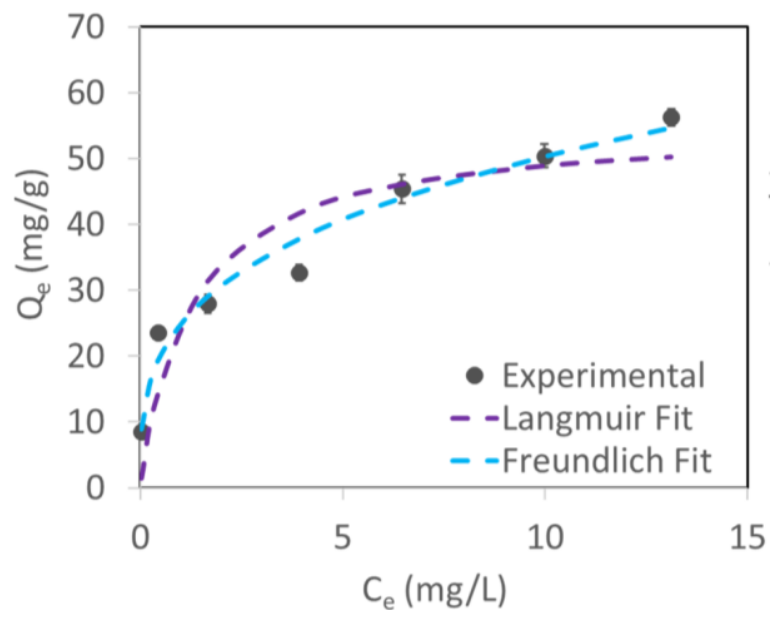

Figure S12. Adsorption isotherm of PFOA $\left([\mathrm{PFOA}]_{0}=1-20 \mathrm{mg} \mathrm{L}^{-1}\right)$ on CDP2 ([Adsorbent $]_{0}=$ $100 \mathrm{mg} \mathrm{L}^{-1}$ ). Experimental data fitted to Langmuir (Purple) and Freundlich (blue) models. Error bars: standard deviation of 3 experiments.

Table S3. Langmuir and Freundlich parameters derived from plots of the GenX binding isotherm of CDP2.

Langmuir Fit

Freundlich Fit

\begin{tabular}{|c|c|c|c|c|c|}
\hline $\mathrm{K}_{\mathrm{L}}\left(\mathrm{M}^{-1}\right)$ & $\mathrm{Q}_{\mathrm{M}}(\mathrm{mg} / \mathrm{g})$ & $\mathrm{R}$ & $\mathrm{K}_{\mathrm{F}}(\mathrm{mg} / \mathrm{g})(\mathrm{L} / \mathrm{mg})^{1 / \mathrm{n}}$ & $\mathrm{n}$ & $\mathrm{R}$ \\
\hline $1.8 \times 10^{6}$ & 5 & 0.94 & 25 & 3.3 & 0.98 \\
\hline
\end{tabular}

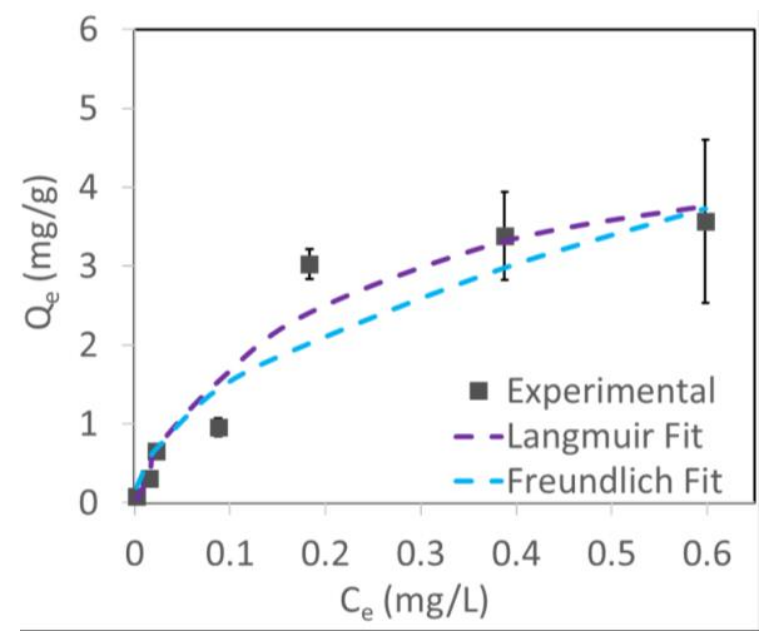

Figure S13. Adsorption isotherm of GenX $\left([\mathrm{GenX}]_{0}=0.01-1 \mathrm{mg} \mathrm{L}^{-1}\right)$ on CDP2 $\left([\text { Adsorbent }]_{0}=\right.$ $100 \mathrm{mg} \mathrm{L}^{-1}$ ). Experimental data fitted to Langmuir (Purple) and Freundlich (blue) models. Error bars: standard deviation of 3 experiments. 


\section{S.6 Comparison of PFOA and GenX Soprtion}

Table S4. Comparison of PFOA and GenX thermodynamic adsorption parameters by relevant materials in the literature.

\begin{tabular}{|c|c|c|c|c|c|c|c|}
\hline \multirow[t]{2}{*}{ Ref. } & \multirow[t]{2}{*}{ Materials } & \multirow{2}{*}{$\begin{array}{l}\text { Amine } \\
\text { group }\end{array}$} & \multirow{2}{*}{$\begin{array}{l}\text { Surface } \\
\text { Area } \\
\left(\mathrm{m}^{2} \mathrm{~g}^{-1}\right)\end{array}$} & \multirow{2}{*}{$\begin{array}{c}\text { Target } \\
\text { PFAS }\end{array}$} & \multirow{2}{*}{$\begin{array}{c}\text { Initial PFAS } \\
\text { concentration } \\
\left(\mathrm{mg} \mathrm{L}^{-1}\right)\end{array}$} & \multicolumn{2}{|c|}{ Langmuir Isotherm } \\
\hline & & & & & & $\mathrm{Q}_{\mathrm{m}}\left(\mathrm{mg} \mathrm{g}^{-1}\right)$ & $\mathrm{K}_{\mathrm{L}}\left(\mathrm{M}^{-1}\right)$ \\
\hline $\begin{array}{l}\text { This } \\
\text { work }\end{array}$ & CDP1 & Yes & 169 & $\begin{array}{l}\text { GenX } \\
\text { PFOA }\end{array}$ & $\begin{array}{c}1-200 \\
10-200 \\
\end{array}$ & $\begin{array}{l}222 \\
457 \\
\end{array}$ & $\begin{array}{l}8.8 \times 10^{4} \\
1.8 \times 10^{6}\end{array}$ \\
\hline $\begin{array}{l}\text { This } \\
\text { work }\end{array}$ & CDP2 & No & 78 & $\begin{array}{l}\text { GenX } \\
\text { PFOA }\end{array}$ & $\begin{array}{c}0.01-1 \\
1-20 \\
\end{array}$ & $\begin{array}{c}5 \\
55 \\
\end{array}$ & $\begin{array}{l}1.8 \times 10^{6} \\
3.3 \times 10^{5} \\
\end{array}$ \\
\hline 4 & $\begin{array}{c}\text { Cyclodextrin } \\
\text { copolymer } \\
\text { (DFB-CDP) }\end{array}$ & No & 7 & PFOA & $1-12$ & 33 & $2.2 \times 10^{5}$ \\
\hline 3 & $\begin{array}{c}\text { Covalent } \\
\text { organic } \\
\text { framework } \\
\left(28 \%\left[\mathrm{NH}_{2}\right]-\right. \\
\text { COF })\end{array}$ & Yes & 1900 & GenX & $0.2-100$ & 200 & $6.3 \times 10^{4}$ \\
\hline 5 & $\begin{array}{c}\text { Activated } \\
\text { carbon } \\
(\mathrm{GAC}) \\
\end{array}$ & No & 812 & PFOA & $20-250$ & 161 & $1.8 \times 10^{4}$ \\
\hline 5 & $\begin{array}{l}\text { Activated } \\
\text { carbon } \\
\text { (PAC) }\end{array}$ & No & 712 & PFOA & $20-250$ & 277 & $4.9 \times 10^{4}$ \\
\hline
\end{tabular}

*More complete comparison table for various PFAS removal using different adsorbent materials are available from reference 6 .

\section{S. 7 References}

(1) Lakshminarayanan, P. S.; Ravikumar, I.; Suresh, E.; Ghosh, P. Encapsulation of Halides within the Cavity of a Pentafluorophenyl-Substituted Tripodal Amine Receptor. Inorg. Chem. 2007, 46, 4769-4771. https://doi.org/10.1021/ic062380g.

(2) Ravikumar, I.; Saha, S.; Ghosh, P. Dual-Host Approach for Liquid-Liquid Extraction of Potassium Fluoride/Chloridevia Formation of an Integrated 1-D Polymeric Complex. Chem. Commun. 2011, 47, 4721-4723. https://doi.org/10.1039/C0CC03469J.

(3) Ji, W.; Xiao, L.; Ling, Y.; Ching, C.; Matsumoto, M.; Bisbey, R. P.; Helbling, D. E.; Dichtel, W. R. Removal of GenX and Perfluorinated Alkyl Substances from Water by Amine-Functionalized Covalent Organic Frameworks. J. Am. Chem. Soc. 2018, 140, 12677-12681. https://doi.org/10.1021/jacs.8b06958.

(4) Xiao, L.; Ling, Y.; Alsbaiee, A.; Li, C.; Helbling, D. E.; Dichtel, W. R. $\beta$-Cyclodextrin Polymer Network Sequesters Perfluorooctanoic Acid at Environmentally Relevant Concentrations. J. Am. Chem. Soc. 2017, 139, 7689-7692. https://doi.org/10.1021/jacs.7b02381. 
(5) Yu, Q.; Zhang, R.; Deng, S.; Huang, J.; Yu, G. Sorption of Perfluorooctane Sulfonate and Perfluorooctanoate on Activated Carbons and Resin: Kinetic and Isotherm Study. Water Res. 2009, 43, 1150-1158. https://doi.org/10.1016/j.watres.2008.12.001

(6) Ateia, M.; Alsbaiee, A.; Karanfil, T.; Dichtel, W. Efficient PFAS Removal by AmineFunctionalized Sorbents: Critical Review of the Current Literature. Environ. Sci. Technol. Lett. 2019, 6, 688-695. https://doi.org/10.1021/acs.estlett.9b00659 